\title{
Schriftdiskurse im Johannesevangelium
}

Eine narrativ-intertextuelle Analyse am Paradigma von Joh 4 und Joh 7

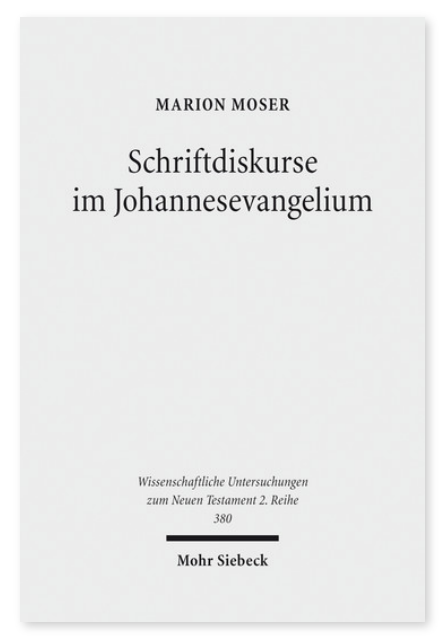

2014. XV, 304 Seiten. WUNT II 380

ISBN 978-3-16-153544-4

DOI 10.1628/978-3-16-153544-4

eBook PDF 109,00€

ISBN 978-3-16-153543-7

fadengeheftete Broschur 109,00€
Marion Moser befasst sich mit einem klassischen Thema der Johannesinterpretation, den Schriftbezügen im Johannesevangelium. Indem sie intertextuelle und narrative Methoden für die Fragestellung fruchtbar macht, rückt ein zentraler, bisher kaum beachteter Aspekt des Schriftgebrauchs des vierten Evangeliums in den Fokus: Zitate und Verweise aus der Schrift werden meistens in Figurenreden eingebettet. Mit dieser Beobachtung verbunden ist eine Reihe von neuen Fragen: Welche Figuren benutzen die Schrift und welche Interpretationen vertreten sie? Welche Folgen hat dies für die Exegese des johanneischen Textes? Steht hinter diesem Schriftgebrauch eine narrative Strategie des Evangelisten und wenn ja, kann sie durch die historische Situation plausibel erklärt werden? In der paradigmatischen Untersuchung von Joh 4,1-42 und Joh 7,1-52 geht die Autorin diesen und weiteren Fragen nach, um daraus anschließend Ergebnisse im Hinblick auf das Evangelium insgesamt zu gewinnen.

Marion Moser Geboren 1982; 2002-09 Theologiestudium an der Universität Zürich; 2009-13 SNF-Doktorandin bei Prof. Dr. Jean Zumstein an der Universität Zürich; 2103-14 Pfarrvikarin in Winterthur Veltheim (ZH, Schweiz); seit Oktober 2014 Pfarrstelle in Adliswil (ZH, Schweiz).
Jetzt bestellen:

https://mohrsiebeck.com/buch/schriftdiskurse-im-johannesevangelium-9783161535444?no_cache=1 order@mohrsiebeck.com Telefon: $+49(0) 7071-923-17$ Telefax: $+49(0) 7071-51104$ 